The use of the smiling option in relation only to semiformal dress may have introduced some bias. For example, the higher preferences for the semiformal nonsmiling doctor may have arisen by its association with a smile on another photograph. Ideally each dress style would have been presented with a smiling and non-smiling version, or the smiling option should have been randomly associated with any of the dress styles. Although these results are representative of the patient population at one hospital in New Zealand, we cannot be sure they would be generalisable to other populations.

In view of differences compared with earlier studies, repeating this study at regular intervals to track secular changes would be of value. We predict that the trend will continue for decreasing popularity of white coats. Although sex interactions were not apparent in this study, looking more specifically for this would be worthy of further study. Similarly, qualitative work that explores why patients react in certain ways would be of interest.

Dress style and manner are well within a doctor's control and therefore can be altered to fit most with patient preference. In the New Zealand setting this would involve dressing in a tidy, semiformal manner in conservative clothing. Asking patients if they prefer to be called by their first name may aid comfort. Doctors should introduce themselves fully and clearly, supple- mented by a name badge worn at the breast pocket. A big smile is a definite advantage.

Contributors: Both authors were involved in the design of the study, analysis and interpretation of the results, and in writing the paper. ML undertook the data collection. She is guarantor.

Funding: Summer studentship grant of $\$$ NZ5000 from the Medical Council of New Zealand.

Competing interests: None declared.

Ethical approval: This study was approved by the Canterbury ethics committee.

1 Short D. First impressions. Brit J Hosp Med 1993;50:270-1.

2 Harnett PR. Should doctors wear white coats? Med J Aust 2001;174:343-4. Gooden BR, Smith MJ, Tattersall SJ, Stockler MR. Hospitalised patient' views on doctors and white coats. Med J Aust 2001;175:219-22.

Wong D, Nye K, Hollis P. Microbial flora on doctors' white coats. BMJ 1991;303:1602-4.

5 Gjerdingen DK, Simpson DE, Titus SL. Patients' and physicians' attitudes regarding the physician's professional appearance. Arch Intern Med regarding the physic

6 McKinstry B, WangJX. Putting on the style: what patients think of the way their doctor dresses. Brit J Gen Pract 1991;41:275-8.

Friis R, Tilles J.Patients' preferences for resident physician dress style. Fam Pract Res J 1988;8:24-31.

8 Blondell RD, Humble RS, Roberts DM. How dress affects perceptions of house officers. Am J Dis Child 1987;141:830.

9 Hennessy N, Harrison DA, Aitkenhead AR. The effect of the anaesthetist's attire on patient attitudes. The influence of dress on patient perception of the anaesthetist's prestige Anarsthesia 1993:48:219-29.

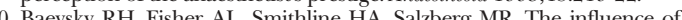
physician attire on patient satisfaction. Acad Emerg Med 1998;5:82-4. (Accepted 30 September 2005)

\title{
Patients bearing gifts: are there strings attached?
}

\section{Sean A Spence}

The giving of gifts is an ancient and widespread human activity. But when the gift is given by a patient to their doctor then there may be ethical and clinical questions to consider

The love embodied in the gift outlives the giver, affirms his life drive, and adds a sense of beauty to the endurance of life.

It was Christmas Eve and the elderly man had walked in his pyjamas through the sleet and snow, until he reached the accident and emergency department. He already knew that he had cancer, but now he was in acute urinary retention. As luck would have it, the house surgeon who came to see him was the one he knew from the ward; they exchanged banter as the younger man sited a catheter. A few nights later, when the house surgeon was back on the ward, the elderly man called him over. He had a gift for him. It was a bottle of champagne. In his working life he had been the head waiter at a famous restaurant; this champagne was the favourite drink of a celebrity who had dined there. The houseman was speechless with emotion; he liked the man and knew he was about to die. It was the first gift he had received from a patient.

\section{The meaning of gifts}

What does it mean when a patient gives their doctor a gift? Often, it means "thank you for being there," especially at a difficult time. ${ }^{2}{ }^{3}$ The elderly man had walked through the snow, despite being in great pain. Perhaps his gift was offered in thanks for relief from that pain. Perhaps it was an attempt at being understood on another level: as someone who was not always old and ill, but who had worked long hours and earned respect as a head waiter. A single gift may have many "meanings." 45

Although gifts from patients to doctors are common, ${ }^{26}$ they have attracted little systematic research. Most of the available literature comprises case reports and series from the world of psychotherapy ${ }^{157}$; cautionary, anecdotal tales from general practice ${ }^{38}$; and small surveys of hospital doctors. ${ }^{46}$ These data are derived largely from the industrialised West, as reflected in the gifts most often reported: bottles of alcohol and boxes of chocolates. ${ }^{36}$ No one has surveyed the impact of gifts on doctors' health, but their impact on nurses' wellbeing has been investigated. ${ }^{9}$

\section{The giving brain}

What does a gift tell us about the patient's mind and brain? At the very least, in an adult, it indicates that they thought about the doctor before their meeting, during the performance of a purposeful act (the acquisition of a gift). Hence, in the language of psychoanalysis, the gift indicates that the doctor persists in the patient's mind as an internal "object" (that to which action or desire is directed ... that to which the subject relates himself). ${ }^{10}$ Indeed, if the gift is taken at face value, then the doctor constitutes a "good object," one eliciting kindness. Alternatively, from a cognitive neurobiologi-
Academic Clinical Psychiatry, Division of Genomic Medicine, University of S5 7JT

Sean A Spence professor of general adult psychiatry s.a.spence@ sheffield.ac.uk BMJ 2005;331:1527-9 


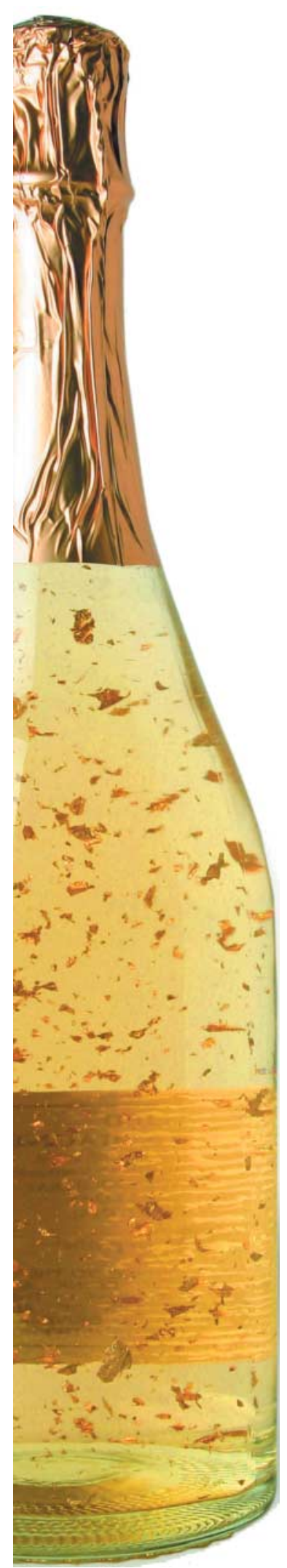

cal perspective, the acquisition of the gift implies the working of higher, prefrontal, brain regions engaged in the formulation of intentions, so called "memories of the future" plan ahead. So the proffered gift carries information, but is it always good news?

\section{A mixed blessing}

According to the Oxford English Dictionary, a gift is "something, the possession of which is transferred to another without the expectation or receipt of an equivalent; a donation, present,"12 so it might seem churlish to "look a gift horse in the mouth." ${ }^{7}$ However, consider some alternative definitions, such as "a fee for services rendered," "something given with a corrupting intention; a bribe."12 Similar ambivalence can be traced back through many languages and cultures. ${ }^{1}$ Things may not be all that they seem.

\section{Two questions}

Here are two questions for doctors receiving gifts from patients: (1) Should any gift be accepted? (2) Should this gift be accepted?

Answering "no" to the first obviates the need for the second and may make life simpler, but there are inevitably pros and cons. ${ }^{13} 14$

\section{Saying no}

Within medical practice, the main argument against accepting gifts from individual patients is the need for justice and equity when dealing with all patients. ${ }^{23}{ }^{34}$ If doctors accept gifts from those who can afford them will they think or behave differently around those who cannot? If doctors accept gifts they may nurture "favourite" patients, and there are risks on all sides. $^{2} 3815$ Doctors may expend more time and effort on selected patients, rules may be bent (for example, on waiting lists or home visits), and "special" patients may precipitate staff rivalries and divided teams. ${ }^{16}$ Doctors may spend relatively less time on other patients and favoured patients may also experience disadvantages: the doctor who becomes a "friend" is no longer impartial and may sacrifice critical judgment (for example, when excluding a neoplasm or a sexually transmitted disease) or even violate boundaries (through inappropriate intimacies). ${ }^{3} 47815$

So, even in the most sincere interaction, the doctor is on a slippery slope when accepting a gift. Moreover, towards the bottom of that slope are more instrumental, exploitative incursions, which can originate from either side (for example, bribery for favourable reports or preferential treatment in lieu of charitable donations). ${ }^{3} 815$ In the United Kingdom, the General Medical Council's (2001) Good Medical Practice warns doctors against soliciting gifts: "You must not encourage your patients to give, lend or bequeath money or gifts which will directly or indirectly benefit you. You must not put pressure on patients or their families to make donations to other people or organisations"17 (italics added). This document advises against deliberately seeking gifts but gives no advice on accepting those that are offered. In contrast, classic psychoanalytical teaching states that gifts from patients should never be accepted because they conceal unconscious motives, which should be interpreted rather than enacted. ${ }^{157}$
Nevertheless, Freud himself accepted gifts and some contemporary psychotherapists have argued cogently for a more nuanced approach. ${ }^{5}$ Refusing a gift risks offending the patient and may seem petty when the gift is small. Also, in psychotherapeutic settings, automatic refusal of a gift may impede certain kinds of progress within the patient (for instance, among those who have difficulty giving and receiving). ${ }^{157}$ Finally, the requirement that a doctor should never accept a gift from a patient may make life difficult in small or isolated communities, where private and professional lives are hard to dissociate (for example, should a doctor's child accept a present from a friend at the village school when the friend's parents are the doctor's patients?).

\section{Saying yes (sometimes)}

Although most authors would accept alcohol and chocolates, they are more reluctant to take money and generally draw the line at intimate or transgressive items (such as pornography). ${ }^{2357818}$ So, most feel that culturally appropriate gifts of low monetary value are relatively "safe." In most organisations the demands of probity require that employees decline gifts that might be seen to influence their judgment. ${ }^{7}$ Hence, no gift should be so valuable that it could be suspected of incurring undue influence: doctors must be seen to be above suspicion.

In addition, regardless of the value of the gift offered, the doctor might wish to reflect upon its meaning to the patient. Even an inexpensive gift might presage problems. So, it could be argued that not automatically refusing all gifts makes life more difficult, incurring a constant need for vigilance.

\section{Why now?}

When exercising discretion over the acceptance of individual items, the following question is helpful: why is the patient bringing their gift now? At Christmas the answer seems obvious. However, the point remains: did they bring a present last year and the year before that? Has anything changed recently?

The scant empirical base we have suggests that patients' gifts are often given in return for an identifiable medical intervention. ${ }^{4}{ }^{6}$ Hence, surgeons may receive more gifts than physicians because of the more tangible nature of their treatments. ${ }^{6}$ The sociological interpretation of this phenomenon is discomforting-namely, the gift is a "tip" for "more than standard" service. This is why doctors do not automatically reciprocate-implicitly or explicitly they understand that the "gift" of their treatment initiated the process - that is, they "gave" first. ${ }^{4}$

Irrespective of how one feels about the paternalism implied by this approach, it suggests that a gift arriving "out of the blue" should be treated with special caution, as the doctor has done nothing (yet) to deserve it. Indeed, the concept of "more than standard service" encompasses a variety of meanings: from those patients seeking to monopolise their doctor to those who are acknowledging that they can be difficult and require "toleration." ${ }^{4}$ The gift may also be a way of balancing power: patients humiliated by the sick role may demonstrate, by their largesse, their importance in the outside world. Alternatively, the gift can constitute a 
"sacrifice," offered to the "power" of the doctor to heal (a kind of magical thinking to keep misfortune away). ${ }^{4}$

The sociological critique is not as materialistic as first seems; this is just as well. For the reduction of gift giving to instrumental exchange can obscure important messages: the man relapsing into mania may bring an extravagant gift; the elderly widow, dying, might say "goodbye" with one,${ }^{19}$ as might the suicidal patient ${ }^{1}$; the erotomanic patient might send their doctor a single theatre ticket, ${ }^{20}$ and the disgruntled patient may give their doctor a medical textbook. The wealth of meaning surrounding the gift may repay reflection.

\section{What is to be done?}

The most appropriate advice is to take nothing for granted and reflect upon the gift and its timing. A polite refusal may be preceded by reference to the ethics of medical practice or could emphasise that declining a gift does not equate to rejecting the patient. Whatever the outcome, a thank you note is appropriate. ${ }^{4}$ Keeping a record of all gifts offered or received and discussing the matter openly with colleagues promotes transparency.

\section{The intangible}

Finally, doctors and their colleagues receive other "gifts" from patients all the time, ${ }^{21}$ without the donors' awareness, such as the vicarious satisfaction the doctor derives from their patients' recovery or the deep impression they leave behind when showing great courage in the face of suffering-as with the elderly man who walked in retention through snow, on Christmas Eve, until he reached the emergency department.

Competing interests: None declared.

1 Stein H. The gift in therapy. Am J Psychother 1965;19:480-8.

2 Lyckholm LJ. Should physicians accept gifts from patients? JAMA 1998; 280:1944-6.

Capozzi JD, Rhodes R. Gifts from patients. J Bone Joint Surg Am 2004; 86A:2339-40.

4 Drew J, Stoeckle JD, Billings JA. Tips, status and sacrifice: gift giving in the doctor-patient relationship. Soc Sci Med 1983;17:399-404.

5 Smolar AI. Reflections on gifts in the therapeutic setting: the gift from patient to therapist. Am J Psychother 2002;56:27-45.

6 Levene MI, Sireling L. Gift giving to hospital doctors-in the mouth of Levene MI, Sireling L. Gift giving to
the gift horse. BMJ 1980;281:1685.

7 Hundert EM. Looking a gift horse in the mouth: the ethics of gift-giving in psychiatry. Harv Rev Psychiatry 1998;6:114-7.

8 Nisselle P. Danger zone-when boundaries are crossed in the doctor-patient relationship. Aust Fam Physician 2000;29:541-4.

9 Cheung ST. The effects of chocolates given by patients on the well-being of nurses and their support staff. Nutr Health 2003;17:65-9.

10 Rycroft C. A critical dictionary of psychoanalysis. London: Penguin, 1972:100 (first published 1968).

11 Ingvar DH. 'Memory of the future': an essay on the temporal organization of conscious awareness. Hum Neurobiol 1985;4:127-36.

12 Oxford English dictionary. Oxford: Oxford University Press, 2005.

13 Andereck W. Point-counterpoint: should physicians accept gifts from their patients? Yes: if they are given out of beneficence or appreciation. West J Med 2001;175:76.

14 Weijer C. Point-counterpoint: should physicians accept gifts from their patients? No: gifts debase the true value of care. West J Med 2001;175:77.

15 Nadelson C, Notman MT. Boundaries in the doctor-patient relationship. Theoretical Medicine 2002;23:191-201.

16 Main TF. The ailment BrJ Med Psychol 1957:30:129-45.

17 General Medical Council. Good medical practice. London: GMC, 2001:17. Committee on Bioethics. Appropriate boundaries in paediatrician-
family-patient relationship. Paediatrics 1999;104:334-6.

19 Kellehear A, Lewin T. Farewells by the dying: a sociological study. Omega 1988-1989;19:275-92.

20 Berrios GE, Kennedy N. Erotomania: a conceptual history. History of Psychiatry 2002;13:381-400.

21 Kline NE. Gifts from children.J Paediatr Oncol Nursing 2002;19:1.

(Accepted 4 October 2005)

\section{Physician, know thyself}

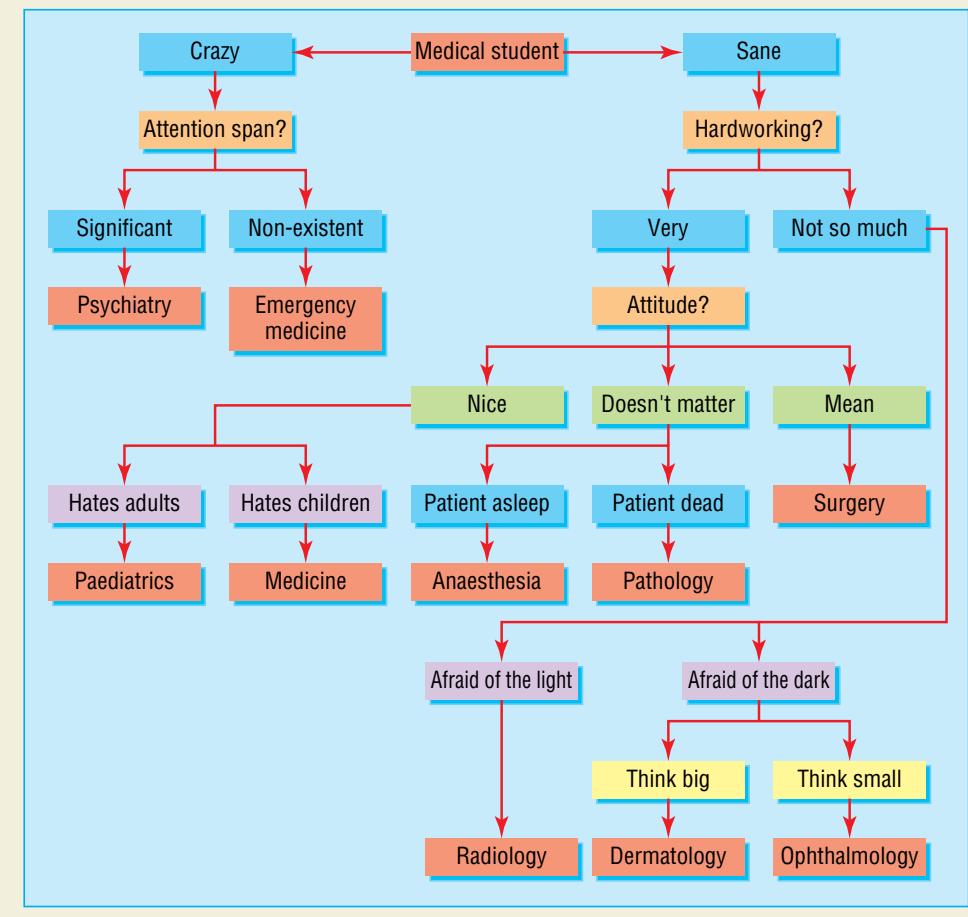

As a resident physician working in a large academic medical centre, I am in frequent contact with medical students, many of whom feel apprehensive about choosing their future medical specialty. Students complain that they need balanced career guidance extending beyond "my specialty is the best" expressed by many doctors. Inspired by my interactions with residents training in all major specialties, I have created an algorithm to guide students' choice of specialty on the basis of their personality characteristics. The algorithm has been well received at my institution by students and residents alike, many of whom exclaim: "That is so true."

I provide the algorithm in the hope that it will be equally useful to the journal's readers.

Boris Veysman resident, Yale School of Medicine, New York University, New York, USA (boris.veysman@med.nyu.edu) 